\title{
The Linnaean Hierarchy and 'Extensional Thinking'
}

\author{
L.N. Vasilyeva*,1 and S.L. Stephenson ${ }^{2}$ \\ ${ }^{1}$ Institute of Biology and Soil Science, Far East Branch of the Russian Academy of Sciences, Vladivostok 690022, Russia \\ ${ }^{2}$ Department of Biological Sciences, University of Arkansas, Fayetteville, AR 72701, USA
}

\begin{abstract}
The Linnaean Hierarchy has been opposed from a number of different perspectives, but most of this opposition was based upon the confusion of two aspects of every taxon - extension and intension. These aspects account for its dual nature of simultaneous change and constancy. "Constancy" is apparent only in the differences that exist among groups of organisms; these differences appear in the very first origin of taxa and persist throughout their entire evolutionary history. The sequence of differences over time is the only basis upon which to judge the history of the organic world. The Linnaean system addresses this sequence by attempting to distribute these differences among hierarchical levels. Taxonomic hierarchical levels, or ranks, do not imply a rigid adherence to certain kinds of characters, since characters can change their rank during group evolution. As such, taxonomic levels can serve only as a tool to coordinate chaotically segregated groups of organisms.
\end{abstract}

Keywods: Taxonomic philosophy, phylogeny, phenetics, typology, essentialism, evolution.

\section{INTRODUCTION}

Ever since the publication of the book entitled "The poverty of the Linnaean Hierarchy" [1], the idea of writing a paper with the title of "The richness of the Linnaean Hierarchy" has been in the back of our minds. Actually, the paper under a similar title ("The treasure of the Linnaean Hierarchy") was written as a review of the book itself [2], but the only treasure found was Linnaean nomenclature. Otherwise, the author expressed an opinion, shared with many other biologists, of the "bad philosophical foundations" of the Linnaean Hierarchy.

The problem relates to the fact that Linnaeus is said to have expanded the existing "Aristotelian taxa of species and genus" by dividing the animal and vegetable kingdoms into a hierarchy of classes, orders, genera, species and varieties. However, it is commonly thought that taxonomic ranks have no ontological basis [2]. In this paper, we shall try to show the contrary to be the case. Not only do taxonomic ranks have an ontological basis, they are steps in the evolutionary differentiation of the organic world. Each rank is distinguished by particular characters, and this character hierarchy is the only evolutionary constituent in the natural system of organisms. The taxonomic hierarchy reflects a sequence in the appearance of characters over time and, as such, the hierarchy is history [3].

Historians of biology who regard Linnaeus in a favorable light tend to dissociate the Linnaean system and Aristotelian logic; they indicate that there is no evidence that Linnaeus studied logic at all [4]. Moreover, Linnaeus was supposed to certainly proceed by the method of exemplars ['type' specimens] [5] and thus did not follow the logical definition of

*Address correspondence to this author at the Institute of Biology and Soil Science, Far East Branch of the Russian Academy of Sciences, Vladivostok 690022, Russia; Tel: (4232) 375239; Fax: (4232) 310193;

E-mail: vasilyeva@biosoil.ru taxa defined by certain characters. In other words, the approach he used is identified as an empirical (or 'good') typology that is divorced from his 'bad' typology, usually described as an example of out-dated essentialism and opposition to evolutionary views $[1,6]$.

Here again, the 'treasure' of the Linnaean Hierarchy associated with nomenclature surfaces, but the 'method of type specimens' appears to be most useful for coordinating taxonomists who describe new species and are involved in priority debates. 'Type specimens' definitely have nothing to do with coordinating taxa within the context of a biological system, and the latter was Linnaeus's ultimate purpose. Curiously, the nomenclatural rules of Linnaeus that are considered good enough are rejected by Phylocode adherents who propose the use of a 'phylogenetic nomenclature' [7-10]. Simultaneously, this 'phylogenetic nomenclature' is expected to destroy the 'essentialist grounds' of the Linnaean Hierarchy, but the current 'nomenclatural war' is far removed from the essentialist philosophy underlying the hierarchical system of living beings. In fact, the term 'phylogenetic' should not be applied to nomenclature, since it is only applicable to a system that is not improved by the Phylocode.

One could make the point that it is really impossible to "free taxonomists from the bonds of ancient traditions" for a "reorganization of the very core of biological taxonomy" [11]. Even if Linnaeus had unknowingly embraced ancient traditions, this made him the 'genius of order' [12]. Notwithstanding how many errors exist in the empirical Linnaean system, the application of Plato's ideas to biological systematics will be always called the 'Linnaean Hierarchy'.

\section{INTENSION AND EXTENSION IN BIOLOGICAL SYSTEMATICS}

Linnaeus's ideas were subjected to early challenges, ranging from transformism (Buffon), 'idealistic typology' (Goethe) and even systematics (Adanson). Later, the global 
conflict of 'ideologies' followed when Darwin "dealt the death blow to essentialist thinking" [13], and Linnaeus is still under fire today. This could be referred to as a struggle between 'chaos' and the Linnaean ordering structure; this situation also reminds one of a well-known dichotomy between the 'Dionysian' and the 'Apollonian' spirits, and it is not without reason that "Linnaeus's youthful face is seen on the body of Apollo" [1] in the frontispiece of his Hortus Cliffortianus. Linnaeus's views were also opposed as 'essentially static and classical' in contrast to 'dynamic and romantic' ones [12]. However, real 'opposition' exists between two aspects of each taxon, namely intension and extension.

Although the terms 'intension' and 'extension' were formulated in the field of general semantics [14], they found another application in biological systematics, where they are defined as follows: 'intension' refers to a set of properties common to a group of objects, whereas 'extension' refers to a set of objects in the group [15]. These terms are somewhat misleading, since the prefix 'ex-' seems to imply some 'external' thing, but 'extension' is an internal set of members of a group. On the contrary, the prefix 'in-' seems to imply some internal 'pivot' but, in actual sense, 'intensions' are differences among groups, that is, they seem to show external boundaries of groups.

The consideration of 'extension' in its proper meaning (a set of group members) is useless for the construction of a system, but it generally can be used to designate the content of a group. There has even been a discussion of the 'extensional thinking' of phylogeneticists [16] who considered relationships between ancestors and descendants within a group. Extensionally, the taxonomic hierarchy consists of groups included in other groups; it was described as an 'inclusive hierarchy' [17]. Intensionally, this hierarchy consists of characters that distinguish groups at different levels; it has been described as an 'exclusive hierarchy', since a lower rank is not a subdivision of a higher rank [17].

If an isolated group is under consideration, its 'intension' might be some 'common properties' that are simply chosen arbitrarily. However, if one is aiming at the system of interconnected groups, 'intensions' cannot be arbitrary. Thus, the endogenous type of spore formation (in asci) is an 'intension' of the phylum Ascomycota, while the exogenous type of spore formation (on basidia) is an 'intension' of the phylum Basidiomycota. Fungi of both phyla share common properties that cause them to belong to the kingdom Fungi, but those properties comprise an 'intension' of that kingdom and can be found only by comparing it with other 'kingdoms'.

In other words, the 'intension' becomes a hierarchical notion in the system of organisms and designates only such common properties that distinguish a particular group from other groups of the same hierarchical level. Such a sense of 'intension' corresponds to Linnaeus's essential character: "The essential character as a unique idea distinguishes a genus from those of the same kind included in the same natural order" ("Essentialis character unica idea distinguit Genus a congeneribus sub eodem oedine naturali" - Philosophia Botanica 187 , italics added).

Unfortunately, the English version of "Philosophia Botanica" [18] translates 'unica idea' as 'unique pattern', and the sense is changed completely. A unique 'idea' in connection with the delimitation of taxa at some hierarchical level reminds one of many of Plato's dialogues, where 'idea' (eidos, 'essence' - 'form' in English translations) is a distinguishing character covering opposite states (cf. Parmenides 132c-d). If one turns to Aristotle's phrases-"definition is the formula of the essence" and "definition is the formula which comprises the differentiae" (Metaphysics, Z1031a, 10-15; Z1038a, 5-10, italics added) - the identity of 'essence' and differences follows again.

A 'unique idea' of a certain hierarchical level is of real importance for biological systematics, since it implies the possibility of rank coordination. For example, taxonomists use a diverse array of characters to describe numerous species in a genus, but all of these species could belong in the same ('species') category only if they are segregated by combinations of states of the same set of characters. Such a set of characters corresponds to Plato's 'idea', since its plenitude exceeds partial ('imperfect') realizations in states that often exclude each other.

Interestingly, Ereshefsky [1] regarded similar views expressed by Aristotle with approval: "Real essences are allowed to have various instantiations, and some instantiations may even lack a visible manifestation." Such a lack of 'visible' manifestations implies that some combinations of delimiting characters have not yet been found. Ereshefsky [1] even considered Aristotle's "method for discovering such essences" to be "not one of pure logical analysis but an empirical one that involves the consideration of a number of traits."

This opposition of the 'empirical method' in Aristotle's biological works and "the method of dichotomous division" introduced in his Metaphysics and considered to be directed towards "dividing a higher group according to a single differentia" [1] is a clear illustration of extensional and intensional 'thinking' in systematics.

Linnaeus's thinking was, of course, intensional ('essentialistic'), but he also tried, instead of initially dividing a higher group according to a single differentia, to divide it "along many differentiae simultaneously" [1]—as is also the case in Aristotle's empirical approach. When Linnaeus discussed a number of generic characters, such as the shape, the position, and the relative size of different parts of flower (calyx, corolla, stamens, etc.), he wrote about different combinations of states of these characters and even calculated the number of possible genera (Philosophia Botanica 167). In accordance with a consideration of several characters, genera could be arranged in a combinatorial space of prognostic value, and that is why "a system by itself indicates even plants that are omitted; which enumeration in a catalogue never does" (Philosophia Botanica 156).

\section{WHEN "THE GENUS MAKES THE CHARACTER"?}

Evidently, a hierarchical structure consisting of intensions of taxa at different levels is constructed when organismal traits are considered. In systematics, organisms could be described only by properties or 'characters', while every taxon is characterized by a certain combination of traits. Nevertheless, some modern biologists demand a shift "from organismal traits to phylogenetic relationships" [11]. Such a false opposition dominates many attacks on the 'Linnaean Hierarchy" but, actually, 'traits' as plesiomorphic and apomorphic character states are taken into account when 
'phylogenetic relationships' are established between ancestors and descendants. Moreover, any character in its diversity of states constitutes a very strong relationship between organisms, since it holds them in a kind of unity. (JeanBaptiste Lamarck spoke of "all the commonalities by which beings hold together, the one to the other" [13]).

Paradoxically, other biologists consider 'characters' not to be important in taxonomy because of Linnaeus's statement: "a character does not make a genus, but the genus makes the character". However, they always forget to cite the remainder of this aphorism where the value of a character increases: "A character does not exist to form a genus, but to recognize it". ("Scias Characterem non constituere Genus, sed Genus Characterem... Characterem non esse, ut Genus fiat, sed ut Genus noscatur" - Philosophia Botanica 169, italics added).

Actually, "the genus makes the character" for a short time in the classification procedure. The first step in this procedure is the creation of tentative genera and families, sometimes using common features of species. At the first step, these common features comprise 'intensions' of higher groups but do not define them, that is, they do not indicate their proper place in the hierarchy. The second step in the classification procedure is the testing of tentative groups for rank equality. For such testing, one should find differences between 'genera' and 'families', often created disparately, and determine how often these differences are considered in their delimitation. Thus, a paradoxical situation arises: 'genera' already exist (although not all of them are true 'genera' with respect to each other, since some might be 'subgenera' or higher taxa), but one seeks defining characters by comparison of 'genera' - as if "genera do make characters".

The testing of tentative 'genera' for rank equality represents a posteriori weighting of characters. One should identify a set of characters such that all taxa of supposedly generic rank are characterized by different combinations of their states. Usually, several of the most frequent delimitative characters, especially multi-state ones, are enough to retain many groups as natural 'genera', whereas some artificial (chaotically segregated) 'genera' should be lumped. Linnaeus described such a process as follows: "Artificial classes are substitutes for natural ones, until the discovery is made of all the natural classes..." (Philosophia Botanica 160).

After application of this testing procedure, some sets of characters become 'essences' serving for recognition of genera or families and defining taxa at certain levels in the hierarchy. Of course, Linnaeus did not have a clear idea of $a$ posteriori weighting of differences for the construction of a natural system, but he understood the importance of the reconsideration of genera: "Every genus... is not to be capriciously split or stuck [to another], for pleasure, or according to each man's theory..., especially a posteriori" (Philosophia Botanica 159).

The insistence of Linnaeus on the provisional status of his taxonomic groups has already been noted: "Linnaeus was emphatic that his natural arrangements were only fragments of a natural method, which could not be completed until all plants were known" [19]. Evidently, a posteriori weighting of differences requires a lot of provisional groups and, of course, it would be ideal to compare "all known plants".
However, even partial-although necessarily extensiveknowledge can improve the existing system.

Therefore, the search for 'essence' uniting taxa at a given level (such an 'essence' has been called a 'hierarchical type' [20]) leads to a considerable increase of system naturalness, and here it would be useful to distinguish between the concepts 'natural system' and 'natural groups'. Groups themselves - even before testing for rank equality - could be quite natural (based on 'common descent') but assigning incorrect ranks to them leads to an artificial system and, consequently, to a bad understanding of their history. That is why correct ranking is most important for acquiring accurate knowledge of the actual organization of biodiversity-it produces a true "system, without which botany is chaos" (Philosophia Botanica 156).

Considerable prejudice surrounds Linnaeus "as an arch maker of artificial systems" [13]. First, the so-called 'principle of continuity' (that is, there are no gaps in nature) was thought to be "a radical departure from the essentialist thinking" [13] attributed to Linnaeus particularly. Second, in the context of continuity, the construction of a 'natural series' was associated with a 'synthetic' approach to classification. Third, a 'synthesis' was referred to as the progressive grouping of species into genera, genera into families, etc., while the sequential subdivision of taxa was termed an 'analysis'. It is a common belief that Linnaeus's 'essentialist thinking' has nothing to do with the 'natural method' associated with continuity.

However, Linnaeus himself wrote that "nature does not make leaps" (Philosophia Botanica 77), which suggests that he understood the 'principle of continuity'. The 'natural series' could be easily traced in character transformations from state to state at every hierarchical level, and 'essences' of taxa represent such series explicitly (genealogical relationships between taxa of the same rank within a combinatorial 'character space'). The 'upward classifications' ('synthesis') and 'downward classifications' ('analysis') could be equally artificial without the application of a testing method (a posteriori character weighting).

The unification and subdivision of groups are not different 'classifications'; they really represent nothing more than different directions along the same pathway. In the framework of content (extension), the grouping of lower taxa into higher ones is not a 'synthesis', since the result is only a sum of the members of the higher taxon in question. The aim of synthetic thinking is the conciliation of opposites, which is realized only in 'hierarchical types' ('hierarchical essences').

Sometimes, the terms 'inductive' and 'deductive' are used for 'upward' and 'downward' classifications, but this is also misleading. The mere subdivision of a higher taxon into lower ones cannot be 'deductive' at all, since 'deduction' means a prognostic conclusion relating to particular taxa on the basis of available diversity. This is only possible when a higher taxon is subdivided using the 'essential' characters distinguishing lower taxa that might be arranged at the 'crossroads' of those characters, and some combinations are omitted or predicted. That is why 'essences' are mostly associated with subdivisions and were more visible to Linnaeus.

The recognition of subdivisions does not in itself make Linnaeus's system 'artificial', but the latter has also been 
challenged from another perspective. Some critics have labeled his "sexual system scholastic and artificial and contrary to the notion of nature's great chain" [21]. However, on the one hand, the employment of floral elements as characters has nothing to do with the ambiguous notion of "nature's great chain" (see the next section), and, on the other hand, Linnaeus intuitively found multi-state characters that always have the greatest weight in rank coordination. He used the combinations of their states correctly for groups of the same level, and it is no coincidence that many of his natural species and genera have persisted to the present day.

It has already been noted that in the Linnaean system, all species taxa are comparable and distinguishable from all other types of taxa [1]. Indeed, all species taxa should be intensionally comparable, that is, they belong to the same level, since they are defined by state combinations of the same character set. This does not preclude a great extensional inequality of species (and higher groups), since they could be large or small, divided into subordinate units or not, etc. As for the fact that species taxa are distinguishable from all other types of taxa, the statement also refers to intensions that are different at other hierarchical levels.

\section{THE LINNAEAN HIERARCHY AND THE DEVEL- OPMENT OF ORGANIC WORLD}

"There is the idea of a scala naturae - the great chain of being - in which the natural world is arranged in a series from the simple to the complex, imperfect to perfect, hydra to human" [13] Such an idea seems to be antagonistic to the Linnaean hierarchy that supposedly reflects only divisions of the organic world, and divisions "disturb relationships and destroy the natural order" [13].

However, the Linnaean hierarchy corresponds more properly to the real development of the organic world. Such a development proceeds as a differentiation or a natural splitting, and, as widely accepted, 'speciation' begins with the isolation of populations. Even the secondary symbioses of earlier differentiated units could be considered as 'splitting', since new organisms appear to be different from previously existing ones - they became separated in a natural manner.

Once upon a time, the "universal gene pool (the common ancestor)" split into 'individual pools'-Bacteria, Archaea and Eucarya [22]; this event can be illustrated as three expanding cones emerging from a single point (Fig. 1). The expansion represents the increase of living beings in number within each domain, with each cone containing both extant and extinct forms.

Furthermore, within each domain, its own particular processes of differentiation occurred. Thus, the sudden appearance of most animal phyla during the "Cambrian explosion" [23] could be illustrated as several smaller cones inserted within the Animal Kingdom. As a result of particular differentiation, some 'cones' contain primitive organisms, while others are filled with complex forms. Of course, the differentiation within the Fungal Kingdom would be expected to be quite different, since the combination of heterotrophic and osmotic types of nutrition closed some of the evolutionary pathways that were open to animals or plants.

In general, as this differentiation of the organic world occurred, this world was splitting in a manner similar to an egg during embriogenesis, and 'organs' (higher taxa) were initiated prior to the 'cell masses' (lower taxa) that comprise these 'organs' in an 'adult' state. The characters distinguishing highest taxa (domains) are the oldest and have persisted from their very appearance until the present day. The same holds true for characters distinguishing animal phyla from the 'Cambrian explosion' or plant phyla from the Devonian period.

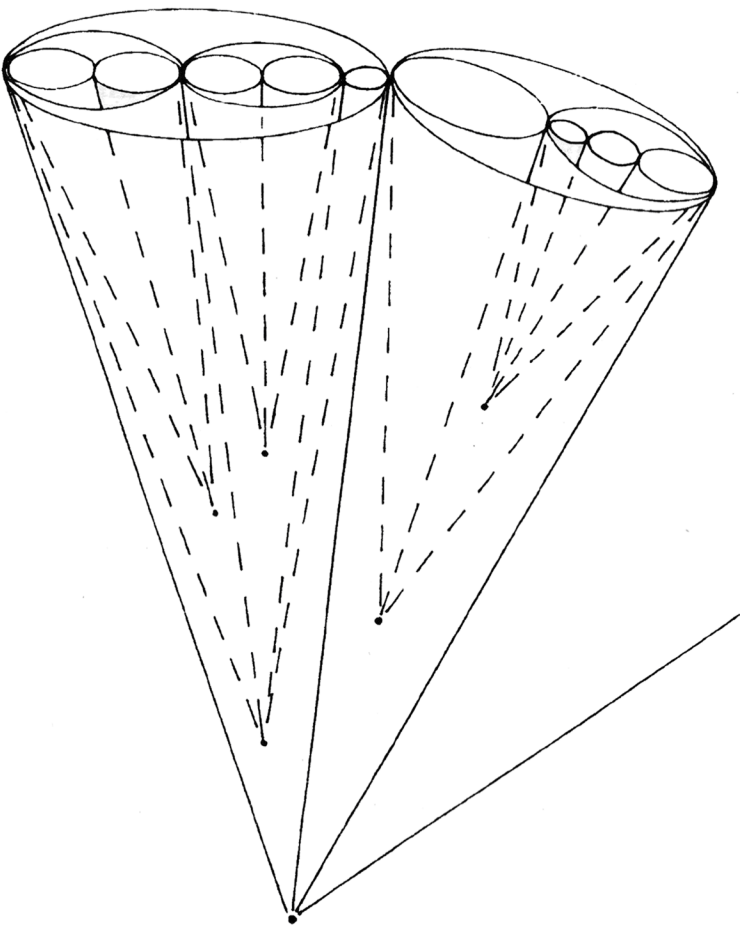

Fig. (1).

The differentiation of the organic world can be illustrated by a simple 'hierarchical model of evolution' (Fig. 1), but doing so has some important consequences. First, there is no 'scala naturae' (the great chain of being) in the sense that a human occupies the highest step of the ladder. A human, as is the case for any other being, exists within its own 'cone' which is inserted within a larger 'cone' (Hominidae), the latter being part of even larger one (Primates), etc.

Second, any statement indicating that 'divisions' disturb relationships and destroy the natural order is not true at all. In actual fact, 'divisions' create a natural order, and such an order has a hierarchical structure. As such, the linear sequence of distinguishing characters having different ages could only be called a 'scala naturae', but it is not a 'chain of beings' and this chain does not proceed from 'simple' to 'complex'. Is it possible to call the most ancient characters distinguishing domains 'simple' in comparison with minor characters distinguishing modern species?

Therefore, the hierarchical model of evolution could be expressed in the Linnaean hierarchy both extensionally and intensionally. It does not matter that Linnaeus himself did not have such evolution in mind; Darwin [24] explained the Linnaean structure in evolutionary terms: "the forms of life throughout the universe become divided into groups subordinate to groups". 
The most important consequence of this world view is that each group of organisms is variable and stable simultaneously. The content (extension) of groups always varies, often very strongly (one can compare, for example, the Devonian and modern composition of the Plant Kingdom), but the intensional relationships between groups are the same during the course of their evolution. Darwin [24] described this situation as the same "genealogical arrangement" between existing groups at each successive period of their modification.

The most curious consequence of this world view is that the organic world is always disintegrating extensionally, while the differentiating groups are bounded by an intensional hierarchical structure that is the same, although expanding. Just this 'pivot' consisting of sequentially appearing differences contains the common descent of all groups. In other words, evolution can be proved from an intensional ('essentialist') perspective, while evolutionists, who are strongly against 'essentialist thinking', are usually up to their eyes in extensions.

When the Modern Evolutionary Synthesis is praised for the concept replacement and the understanding of species as "population lineages" instead of "groups of similar organisms" $[25,26]$, this results in the attention of some biologists being redirected from the intensional aspect of a species to its extensional aspect. Of course, intensions could not be ignored completely in taxonomy, and it is not without reason that 'population thinking' still strives for an absolute 'species criterion'.

As the hierarchical model of evolution shows, there could not be such a species criterion, since the same distinguishing characters gradually increase their rank during the differentiation of the organic world. Nevertheless, the idea of "getting rid of species" [27] is surely premature. If many groups are segregated as 'species' at the present stage of evolution, the only thing that remains to be done is to test these 'species' for rank equality (at least, in the same families). In this way, we can come to a more natural system.

\section{THE 'EXTENSIONAL THINKING' OF PHYLOGE- NETICISTS}

Because the character hierarchy retains the common descent of many-leveled groups, the hierarchical system of organisms could be genealogical (phylogenetic), but, nonetheless, it does not show ancestors and descendants. (The same case is a living being: can anybody say that brain originates from heart or liver? The answer is 'no', but brain, heart and liver have a common origin.) In other words, the construction of a natural system, which reflects evolutionary differentiation, does not require the tracing of relationships between ancestors and descendants of the same level.

Each point of divergence in a hierarchical model of evolution corresponds to a certain set of characters, whose state combinations could define a considerable number of groups of equal rank. These groups might be arranged in a combinatorial manner where realized and non-realized possibilities are seen. The character changes from primitive to advanced states could be traced along each 'column' of a combinatorial 'table'. Such a tracing - on the same plane at each levelcould be rather informative for the understanding of evolution in short sequences of equally ranked groups, but it is not the sequence of states but the position of characters in a hierarchy that is of primary importance.

Modern phylogeneticists seem to have understand very well that the classificatory Linnaean hierarchy and the relationships between ancestors and descendants are 'perpendicular' to each other. However, their mistaken belief that the natural system could be constructed only from those relationships has caused a very severe criticism of Linnaeus's views. It has been stated that Linnaeus represents an "outdated and misguided classification system" [27].

Either the direct conflict between the Linnaean hierarchy and the principle of descent [25] or the 'incompatibility' of the former with phylogenetic systematics $[28,29]$ have been maintained. Since the central role of taxonomy is said to be the communication of phylogeny [30, 31], some authors declare the necessity of exploring 'alternatives' to the Linnaean hierarchical system [32].

However, there is no real conflict between the Linnaean hierarchy and the principle of descent, as can be seen from the hierarchical model of evolution. The conflict exists between two phylogenies. The Linnaean hierarchy is a 'vertical phylogeny' that reflects the sequence of different characters that appear during evolutionary differentiation. 'Alternative phylogenetic systems' are 'horizontal phylogenies' and involve sequences of character states; they reflect relationships of groups at each level within the Linnaean system.

Horizontal phylogenetic relationships are often illustrated by cladograms. These are supposed to show 'hierarchies', but the latter are false hierarchies that result in the 'subordination' of equally ranked groups. Cladograms deal with socalled 'terminal taxa', which might be species, genera, families, etc., and "there are about 20 million possible phylogenetic trees for 10 terminal taxa" [33]. Such a situation strongly suggests the problems inherent in the chaotic use of differences. Tentative 'species' or 'genera' could be arranged 'phylogenetically' at will, and few individuals would be interested in knowing whether or not terminal taxa are really equal in rank.

'Phylogenetic systematists' and 'evolutionary systematists' share 'extensional thinking' directed towards the content of taxa. This is especially evident from the side of nomenclature, since the demands to replace the Linnaean rules of naming taxa with the approaches inherent in the Phylocode come to considerations of extension.

There is an opinion that much of the debate about phylogenetic nomenclature revolves around the "idea of stability", whether it is the stability of the content of a named taxon or the stability of the taxon name. Linnaean nomenclature is supposed to achieve the former, phylogenetic nomenclature the latter [34]. However, "stability of content" of a taxon is a fantastic notion that cannot be associated with Linnaeus' views.

In order to achieve 'stability of names', phylogeneticists oppose the practice of naming families and orders after the 'type' genus, but their interpretations of the Linnaean definitions are incorrect. Phylogeneticists describe the "Linnaean definitions" as follows: "The implicit definition of the name 'Asteraceae' is something along the lines of the taxon including the genus Aster that is assigned to the category Family', 
and the definition of the name 'Liliales' is something along the lines of 'the taxon including the genus Lilium that is assigned to the category Order"' [25].

However, from a taxonomic point of view, the above examples are not the Linnaean definitions of the groups Asteraceae or Liliales; his definitions should point to characters segregating the Asteraceae among other families or Liliales among other orders: "When defining an order it is not sufficient to list the common characters; one should also list the characters which distinguish the order from all others" [12].

It was not Linnaeus's intention to name families and orders after the name of a 'type' genus [35]. When he went about the process of naming higher taxa, Linnaeus really did NOT "keep the exemplar species [or genera] in mind" [5]. He wrote that "the names of classes and orders should contain a feature that is essential and characteristic" (Philosophia Botanica 253, italic added). It was later that Whewell's [36] insistence on the use of 'type' exemplars and the need to have a "type for our director" instead of a definition became part of taxonomy.

Paradoxically, phylogeneticists ascribe THEIR 'extensional vision' to Linnaeus, criticize HIM for the lack of evolutionary meaning in a 'typical' genus, and simultaneously reject the Linnaean Hierarchy as a "non-evolutionary" structure! In this false opposition, phylogeneticists invented 'phylogenetic'-again, extensional-'definitions' and thus established a very cumbersome practice.

In contrast with 'Linnaean definitions' [25], but, more accurately, in contrast with the convention to name higher taxa after some member of the group in question, phylogeneticists have suggested that one should "define" taxa after two or even three members (two descendants and an ancestor), but, in such an instance, we have only a superfluous convention. Moreover, there cannot be an 'extensional definition' of a group, since definition is the indication of a hierarchical level for a group and could be found only by comparative weighting of differences. From the extensional perspective of the Phylocode, "the linkage to a rank will be $o p$ tional" [9].

In other words, the Phylocode suggestion to legitimate the existing chaos of false 'genera', 'families', 'orders' (that are not comparable in intensions) "opens up a nightmare scenario for the future of systematics" [34], since the 'definitions' through ancestors and descendants do not necessarily involve monophyletic groups.

The concept of monophyly itself in phylogenetic "systematics" is purely extensional. Phylogeneticists think that a monophyletic genus should include an ancestor and all of its descendants [37-39], but descendants of an initial species may represent taxa at different taxonomic levels in accordance with changes of different characters distinguishing groups of the previously originated hierarchical diversity.

Just this type of situation was described by Darwin [24] as follows: "The forms descended from A, now broken up into two or three families, constitute a distinct order... Nor can the existing species, descended from $A$, be ranked in the same genus with the parent $A$ ". The latter refers to the ancestral species, which can be divided into several isolated populations, and there will be a group of species instead just the one. Different characters of the ancestral organism could be changed in each population, but the ancestral species belonged to some genus, family, etc. If its generic features changed, a species representing a new genus would be recognized, but with such being the case, the descendant cannot be ranked in the same genus with the parent $A$. The unification of all descendants into a single genus would result in an unnatural classification. Therefore, the only acceptable definition of monophyly may be associated with defining characters that also show the common descent of members.

Paradoxically, extensional attacks by phylogeneticists upon the Linnaean hierarchy render a 'phylogenetic classification' hopeless. Classification could reflect phylogeny in both intensions (character hierarchy) and extensions (group subordination), but suggestions from the Phylocode are unacceptable. The reactions to 'phylogenetic philosophy' are the negative and fruitless statements that "biological classifications are necessarily entirely human constructs" and "there is no single, true classification inherent in nature that is there to be discovered" [34]. Such pessimism cannot be warranted when considered against the backdrop of the Linnaean hierarchy that might be improved by a posteriori weighting of characters.

\section{THE 'EXTENSIONAL THINKING' OF PHENETI- CISTS}

Since those taxonomists who belong to the 'phenetic school' do not discuss 'relationships' between organisms and, instead, concentrate their attention upon 'characters' (which are also relationships, as noted above), some people think they possess 'intensional thinking' [16], but it is an illusion. In reality, intensional thinking is associated with a hierarchy and different weights of characters, while the 'phenetic school' is supposed to be based on the Adansonian idea of using large numbers of equally weighted characters.

The very rejection of character weighting represents a radical departure from the hierarchical world view. In the hierarchy, many characters are not equal - they are higher or lower in rank, but the whole set of characters might be of importance at each level. In such a case, the state combinations of these characters characterize taxa of the same rank, while character sets represent hierarchical types or 'essences' of the different levels. It was wrongly admitted that the advent of evolutionary theory has done with 'essences' [40]; that is why evolutionists have expressed sympathy towards Adanson, who "abandoned all the tenets of essentialism before evolutionary theory" [40] and stated that "no invariant and essential characters were allowed" [13]. However, there are no invariant character states, whereas characters themselves are 'invariant', that is, they are the same in the course of character evolution from primitive to advanced states.

The ultimate value of Adanson's contribution to systematics has been estimated in different ways by various taxonomists. Initially, his idea of a classification "based on all features of the plant was seen as being a decidedly impracticable approach to the study of nature" [13]. Such an "approach [which was very difficult to implement] had to wait for accessible computer technology, which became available only in the middle of the twentieth century" [13]. Indeed, as a result of this technology, Adanson's method finally received widespread approval, and the so-called nu- 
merical taxonomists began to develop 'Adansonian classification' [41, 42].

Strangely enough, numerical taxonomists had replaced 'all features' of organisms by 'overall similarity', which has a different meaning and does not correspond at all to Adanson's method. Adanson was not guided by 'overall similarity' when he united plants into families. He did just the opposite, since he described species, "not mentioning the resemblances but only noting their differences" [43]. Therefore, he had "described all families and genera, the latter in tables of characters varying at a generic level within a family" [13].

In other words, Adanson constructed families in an extensional way - almost in the same way as phylogeneticists are doing, since characters varying at a generic level could display variations from primitive to advanced states. Of course, the extensional way of forming groups is sometimes solely possible, especially when different stages of metamorphoses apparently lacking common characters should be united. However, once again, the extensional naturalness of groups themselves does not provide a priori a natural and multi-leveled system of relationships between them, and distinguishing characters should be estimated a posteriori for that purpose.

Adanson's views were wrongly understood by founders of the 'numerical school' of taxonomy, probably because the school originated with several non-taxonomists [44]. It is even more unfortunate that his method of creating merely tentative (very often 'artificial') groups was praised as philosophically the "best" one: "Deductive principles... were increasingly rejected, and taxonomists to an increasing extent based their taxa on the totality of characters. This was started by Adanson, but a strongly empirical philosophy characterized virtually all the leading taxonomists of that period. The term 'natural' acquired a new meaning during this period, signifying a classification unbiased by a priori considerations and based on a consideration of the totality of characteristics" [45].

It has been noted by some taxonomists that the Adansonian "natural" method of group formation seems to be in opposition to Linnaean "artificial" system, but this opposition is quite unfounded. Linneaus was also trying to take a totality of characters into consideration and to use a natural method [12]. Linnaeus was known as a scientist who belonged to the great empirical western tradition, and he had no rivals as an observer and describer of sensory objects [46]. However, Linnaeus understood that "all characters" should not be used for the segregation of groups at a single hierarchical level, and if "the fruit-body suffices for at least 5736 genera... it is a mistake to take [into consideration] the habit, colour, size, cotyledons, and other things..." (Philosophia Botanica 167, italics added).

The "philosophy of phenetics" has been said to hold that organisms should be classified solely on their overall similarity to each other and the more characters that are considered, the greater sampling of the genome would be brought into play [44]. However, when extensional thinking prevails, such a "philosophy" results not only in intensionally artificial groups that are wrongly ranked but also in extensionally artificial groups that are heterogeneous in content.
The internal polymorphism of closely related genera and families could be absolutely the same, and this is reflected by Vavilov's law of homologous series in hereditary variation [47]. Thus, the number of similarities in different genera of the family Poaceae exceeds more than a hundred characters, but very few differences exist among those genera. The extensional resemblance of genera is exclusively high, but, nevertheless, taxonomists should not rely upon this 'overall similarity' of their members when genera are segregated.

The "phenetic philosophy" suffers one other deficiency: if phylogeneticists rely upon relationships between ancestors and descendants that are traced only between taxa of the same hierarchical level ('horizontal phylogeny'), pheneticists argue that the real meat of a taxonomic study is working out the phylogeny of the organisms [44]. Thus, phylogeneticists use the 'wrong' phylogeny and pheneticists do not use any phylogeny, whereas both camps fail to see a 'vertical phylogeny' that is equivalent with the taxonomic hierarchy of characters and "the real meat of a taxonomic study".

Pheneticists have stated that the most arbitrary weighting of characters came from assumptions of their supposed phylogenetic significance [44], but all characters are of phylogenetic significance, being different at the various hierarchical levels. Pheneticists also assert that no character should be weighted a priori as more important than any other [44], but even a priori (tentatively) characters can be distributed among hierarchical levels, while the weight of a character is its position in the hierarchy. Many characters distinguishing taxa of the same level are of equal weight, but that should be tested a posteriori.

On the whole, all tenets of the 'phenetic school' of taxonomy expose a sort of 'extensional thinking' that lacks a hierarchical vision. In the framework of phenetic views, an extensional notion of a 'type' has even been suggested. It has been noted that "empirical procedures do not aim at a hypothetical idealistic type" and, instead, they describe a common 'type' as a multidimensional framework, the axes of which consist of the characters considered [48]. This author goes on to say that "such a multi-dimensional representation will have to take into account the variation of a given character among the members within the taxon" [48].

However, since the discussion is about characters varying within the taxon, for example, the generic characters within a family (cf. Adanson's tables of characters), which type is being considered? This cannot be the 'type' of a family, which could be found in comparison with other families, and then in the framework of another multi-dimensional representation (at the familial level). If only the 'combinatorial space' of generic characters is considered, this cannot be a 'type' of a separate taxon, inasmuch as this is a 'type of level', or a 'hierarchical type' [49], while the 'type' of a genus is a particular combination of character states (a single 'box' in the table).

\section{THE 'EXTENSIONAL THINKING' OF TYPOLO- GISTS}

Despite the fact that pheneticists accidentally suggested the notion of a type that could be related to a 'hierarchical type' (a set of characters coordinating taxa at the same level by combinations of states), the accusation of this trend in typological background [44] is unwarranted. Typology did 
seem to experience a number of misunderstandings, since the literature relating to this subject is filled with a mixture of three typologies.

The 'typology' dealing with method of 'type' exemplars serves only for nomenclature; it is irrelevant for the purpose of classification. Equally irrelevant, but more directed towards classification is the trend that could be referred to as 'organismic typology'. The focus of this typology, since Goethe and Owen, has been the search for some 'typical' element whose transformations provide the basis for all of the diversity of parts in organisms. At last, there is true classificatory typology that is the foundation of the Linnaean hierarchy.

Anyone who reads the following paragraph will find all that is wrong about classificatory typology: "Typology was a pre-evolutionary approach to taxonomy, derived from the assumption of the fixity of species. It supposed that, since species had set limits to their variability, they could be taken as varying around a central type species that could be taken as representative of that species for the purpose of classification. This was, in theory, overturned by the Darwinian view of the mutability of species..." [44].

First, when the classificatory typology is kept in mind, it is NOT "a pre-evolutionary approach to taxonomy"; it is quite compatible with evolutionary views, even if it assumes the "fixity of species" in intensions. Second, species have "limits to their variability" even in extensions, since the early stages of changes direct the ways of evolution, but there is NOT any "central type species" that serves as a representative to vary around (this concept is 'borrowed' from 'nomenclatural typology'). Third, any discussion of varying around a "central species" would imply some variability within a genus, that is, a genus extension, and there is nothing "for the purpose of classification" as the latter is exposed in the Linnaean system. Finally, Darwinian theory COULD NOT overturn classificatory typology, and Darwin only suggested an evolutionary explanation of the natural hierarchy.

A rather correct, although negative, description of classificatory typology was provided by Mayr [50] as follows: "According to this concept the observed diversity of the universe reflects the existence of a limited number of underlying 'universals' or types... This [species] concept, going back to the philosophies of Plato and Aristotle, was the [species] concept of Linnaeus and his followers... This philosophical tradition is sometimes referred to as essentialism..."

Mayr wrote about the "species concept", but the "existence of a limited number of underlying universals or types" does not necessarily refer to a single hierarchical level. The concept he mentions actually describes the whole hierarchy, whereas the number of levels and, accordingly, 'hierarchical types' could be limited, indeed, since it is possible to coordinate a considerable number of extensionally unequal taxa at a few levels by using many characters for each of them.

It is only important to use a single set of characters whose state combinations are 'types' of particular taxa of the same level. Of course, the number of 'particular types' at each level is not so limited as the number of levels themselves, but is necessarily limited by the number of characters in use, the number of states, and possible prohibited combinations.
Recently, some papers $[4,51]$ have appeared in which the authors state that Mayr invented "the essentialism story", and one could expect justice to apply with respect to Linnaean classificatory essentialism, or classificatory typology. Alas, a completely different typology, encompassing views of socalled 'idealistic morphologists' and their organismic notions of types (especially 'archetypes') are praised.

Organismic typologists have the deepest 'extensional thinking', since they seek to identify the 'type' of a group within organisms constituting the group. Contrary to real 'hierarchical types' of the Linnaean classification that could be found by character weighting, 'types' of 'idealistic morphologists' are always fantastic models of an organism ("the Idea of a natural being" - [52]) and are useless for classification. Thus, "a synthetic drawing of an archetypal plant" gives a picture of many varying organs from different plants (extension of the Plant Kingdom) incorporated into a single individual [52]. At best, "types could, in some cases, have existed as real ancestral forms" [52], but, it should be emphasized again, there are no 'typical'-ancestral or descendant—beings.

The statement has been made that the 'method of typology' was developed by Goethe and this brought a new approach to the consideration of an organism [53]. Goethe was rather scornful of the Linnaean system [54], but he was not a taxonomist and could not perceive the taxonomic philosophy. The achievements of these great persons are not comparable. For example, Goethe proposed the idea of an 'organ' whose modifications could, in theory, give rise to all parts of a flower and some other plant parts. As such, he tried to reduce diversity to a single element. In contrast, Linnaeus dealt with the available diversity of plants and tried to organize it in a certain-hierarchical-fashion.

It has also been said that "the method of typological comparison" is "independent from the theory of evolution" [53], and the shadow of this kind of typology falls upon the Linnaean hierarchy that reflects evolution. Organismic typology also has taken refuge in a so-called "structuralist approach to classification" $[55,56]$, and it is not surprising that this movement represents an "alternative to current neoDarwinian thought" [57].

When structuralists talk only about "rational morphology", they could be left alone. However, they also cherish ambitions to develop a "rational taxonomy" [58]. The latter involves efforts to reinstate the organism in the theory of evolution and to classify biological forms on the basis of transformations of a "given dynamical structure". The structuralist philosophy is a mixture of Aristotle's 'classificatory essentialism' and his 'organismic essentialism'. Structuralists attempt to use the latter to classify objects, but the enterprise is hopeless from a taxonomic perspective.

"Aristotle believed that all particular things embody... essences" [57], but "particular things" do NOT embody 'essences', since the concept of 'essences' is only relevant to groups of things. It has been thought that the 'essence' of a particular tree is "its basic design" [57], but the same basic design might characterize numerous types of trees that compose a group. Such a design might be an 'essence' of this group, but it is important to remember that if the group under consideration is a 'family', the structuralist's views leave 'ge- 
nus' and 'species' of a particular tree without 'essences', which are necessary for its classification.

It is correct to say that "an important implication of this view is that everything in the world might be classified according to its essential properties" [57], but, as noted above, all characters of things are essential in the hierarchy-only at different levels. By the way, the next sentence in the paragraph seems to be completely irrelevant: "Thus species, according to Aristotle, do not change (or evolve) because their essential properties do not change" [57]. Such a leap from a particular thing to a group (species) is amazing, and here there is also a confusion of organismic and classificatory essentialism.

Species as groups change and evolve (differentiate into subgroups) extensionally, despite the fact that their essential properties (intensional differences from other species) do not change. Therefore, a species can be considered as a 'particular thing', that is, the same evolving unit. Nevertheless, when a species is considered as a thing ("species-as-individual thesis" in modern biology), biologists are, once again, forced to consider its internal 'coherence' (although any species is disintegrating during the course of evolution) instead of searching for its natural place in the system. Those biologists who share the species-as-individual thesis often attack essentialism [59-62], but they are true 'organismic essentialists' and cannot serve as effective judges of taxonomy. In the framework of classification, the individuality - as well as monophyly - of natural groups is associated with 'essences'.

\section{CONCLUSIONS}

The Linnaean Hierarchy — as having supposedly 'bad philosophical foundations'- has been opposed from a number of different perspectives, including what can be referred to as the evolutionary, phylogenetic, numerical and organismal-typological approaches to systematics. All these different perspectives are directed towards the contents of particular taxa (extensions) and seek to discredit Linnaeus's views relating to considerations of the intensions of taxa. Two aspects of every taxon (extension and intension) account for its dual nature of simultaneous change and constancy. "Constancy" is apparent only in the differences that exist among groups of organisms; these differences appear at the very first origin of taxa and persist throughout their entire evolutionary history. The sequence of differences over time is the only basis upon which to judge the history of the organic world. The Linnaean system addresses this sequence by attempting to distribute these differences among hierarchical levels.

Taxonomic hierarchical levels, or ranks, do not imply a rigid adherence to certain kinds of characters, since characters can change their rank during group evolution. As such, taxonomic levels can only serve as a tool to coordinate chaotically segregated groups of organisms. These groups could be very unequal in extensions (large or small), but it is possible to find a set of differences that makes some taxa comparable intensionally (i.e., to be assigned to the same hierarchical level). Such sets of differences at different levels could be referred to as 'rank essences'.

The tentative Linnaean Hierarchy is an intuitive distribution of characters among levels, but it becomes more natural after a posteriori weighting of differences among prelimi- nary taxonomic groups. Even if these groups are natural in themselves (i.e., they are monophyletic and based upon a common descent for all of their members), they do not constitute a 'natural system' until being tested for their hierarchical levels.

The Linnaean Hierarchy corresponds to the development of the organic world through a pattern of differentiation similar to embryogenesis. The diversity within earlier groups inevitably increases during their evolution, and they tend to break up into subordinate groups. When this continuous disintegration of extensions is taken into account, one cannot expect any inner coherent force. The common descent of organisms that are radiating into different ecological niches is conserved in intensions at different levels. Therefore, intensions tie together the disintegrating world and compose a rigid (though expanding) hierarchical structure within it. When evolutionary taxonomists attack the Linnaean Hierarchy, their attention is directed mostly towards extensions.

Since the character hierarchy retains the common descent of organisms, the Linnaean Hierarchy can be genealogical, but it does not require one to "fix" ancestors and descendants for its construction. The Linnaean Hierarchy is a vertical phylogeny that reflects the sequence of differences over time, while ancestors and descendants can be traced only at a single hierarchical level along the lines of character changes from primitive states to advanced ones. This horizontal phylogeny is the only focus of phylogeneticists and the reason why they attack the Linnaean Hierarchy. Moreover, phylogeneticists wrongly attribute to Linnaeus the idea of naming higher taxa (families and orders) after the name of a 'type' genus. Since such a nomenclatural 'type' does not make any evolutionary sense, phylogeneticists state-again wrongly - that the Linnaean system does not have an evolutionary basis. In their attempts to replace Linnaean nomenclature with the Phylocode, phylogeneticists suggest replacing a 'type' genus with two or three genera connected by common descent, but this attitude reminds one of the evolutionary taxonomists with their extensional vision. It should be emphasized that extension considerations do not influence the Linnaean Hierarchy.

The numerical approach to systematics introduced the idea of assigning an 'equal weight' to characters, but this is at odds with the idea of a hierarchy, since the weight (or value) of a character depends upon its position at some particular level. The weakest point in the views of numerical taxonomists is the principle of 'overall similarity' serving as the basis for uniting organisms into groups. In many cases, when closely related taxa (e.g., genera representing the same family) share the same inner polymorphism of characters (Vavilov's law of homologous variation), their 'extensions' are almost the same. This inner similarity greatly exceeds the few differences that usually exist between such groups, but it can lead to the formation of artificial taxa. As a result of concentrating upon extensions, as taxonomists do for other trends, numericists have suggested the concept of a 'type' representing a network of crossing characters (combinatorial space) inside a particular group under consideration. However, such a type cannot be associated with a certain group; if it is placed within a group, it can be called a 'hierarchical type' of a lower level. The hierarchical type is a set of char- 
acters, while the combinations of their states are types of individual groups of the same level.

There are taxonomists who probe even deeper inside taxa; they look inside organisms in search for intensions, types and essences. Organismal typology - the renaissance of 'idealistic morphology' - uses the same words as the classificatory typology of Linnaeus, but it is actually the most dangerous substitute for taxonomic philosophy.

The Linnaean Hierarchy cannot be abolished as an 'outdated system'; despite many empirical errors in Linnaeus's practices, his hierarchy is the application of an ancient concept of 'essences' to biological systematics. As a rule, taxa are composed mostly on the basis of extension considerations, but their unification into a natural system reflecting their history requires intension considerations that reveal 'essences' of different hierarchical levels.

\section{REFERENCES}

[1] Ereshefsky, M. The poverty of the Linnaean Hierarchy, Cambridge University Press: Cambridge, 2001.

[2] Dupré, J. Hidden treasure in the Linnaean Hierarchy. Biol. Philos., 2002, 17, 423-433.

[3] Rosen, D.E. Hierarchies and history. In Evolutionary theory: paths into the future.; Pollard J.W., Ed.; John Wiley Sons: Chichester, 1984, pp. 77-97.

[4] Winsor, M.P. Linnaeus's biology was not essentialist. Ann Missouri Bot. Gard., 2006, 93, 2-7.

[5] Winsor, M.P. Non-essentialist methods in pre-Darwinian taxonomy. Biol. Philos., 2003, 18, 387-400.

[6] De Queiroz, K. Replacement of an essentialistic perspective on taxonomic definitions as exemplified by the definition of "Mammalia". Syst. Biol., 1994, 43, 497-510.

[7] Cantino, P.D.; Olmstead, R.G.; Wagstaff, S.J.; Meng, J. A comparison of phylogenetic nomenclature with the current system: a botanical case study. Syst. Biol., 1997, 46, 313-331.

[8] Moore, G. A comparison of traditional and phylogenetic nomenclature. Taxon, 1998, 47, 561-579.

[9] Cantino, P.D. Phylogenetic nomenclature: addressing some concerns. Taxon, 2000, 49, 85-93.

[10] Laurin, M.; Cantino, P.D. First international phylogenetic nomenclature meeting: a report. Zool. Scripta, 2004, 33, 475-479.

[11] De Queiroz, K. Phylogenetic definitions and taxonomic philosophy. Biol. Philos., 1992, 7, 295-313.

[12] Stafleu, F.A. Linnaeus and the Linnaeans, A Oosthoek's Uitgeversm: Utrecht, 1971.

[13] Stevens, P.F. The development of biological systematics, Columbia University Press: New York, 1994.

[14] Carnap, R. Meaning and necessity: a study in semantics and modal logic, University of Chicago Press: Chicago, 1947.

[15] Buck, R.C.; Hull, D.L. The logical structure of the Linnaean Hierarchy. Syst. Zool., 1966, 15, 97-111.

[16] Dupuis, C. Permanence et actualité de la systématique. II. Le taxonomiste face aux catégories. Cah. Natural., 1988, 44, 50-112.

[17] Mayr, E. The growth of biological thought, Harvard University Press: Cambridge, 1982.

[18] Free, S. Linnaeus' Philosophia Botanica, Oxford University Press: Oxford, 2003.

[19] Cain, A.J. Linnaeus's natural and artificial arrangements of plants. Bot. J. Linnean Soc., 1995, 117, 73-133.

[20] Vasilyeva, L.N. Systematics in mycology. Bibl. Mycol., 1999, 178, $1-253$.

[21] Frängsmyr, T.; Heilbron, J.L.; Rider; R.E. The quantifying spirit in the eighteenth century, University of California Press: Berkeley, 1990.

[22] Woese, C.R. Interpreting the universal phylogenetic tree. Proc. Natl. Acad. Sci. USA, 2000, 97, 8392-8396.

[23] Chen, J.Y.; Cheng, Y.N.; Iten, H.V. The Cambrian explosion and the fossil record, National Museum of Natural Science: Taichung, 1997.

[24] Darwin, C. The origin of species, Penguin Books: New York, 1958.
[25] De Queiroz, K. The Linnaean hierarchy and the evolutionization of taxonomy, with emphasis on the problem of nomenclature. Aliso, 1997, 15, 125-144.

[26] Wilson, R.A. Realism, essence, and kind: Resuscitating species essentialism? In Species: new interdisciplinary essays; Wilson, R.A., Ed.; MIT Press: Cambridge, 1999, pp. 187-207.

[27] Mishler, B.D. Getting rid of species? In Species: new interdisciplinary essays; Wilson, R.A., Ed.; MIT Press: Cambridge, 1999, pp. 307-316.

[28] Løvtrup, S. On species and other taxa. Cladistics, 1987, 3, 157-177.

[29] Sosef, M.S.M. Hierarchical models, reticulate evolution and the inevitability of paraphyletic supraspecific taxa. Taxon, 1997, 46, 75-85.

[30] Lidén, M. Oxelman, B. Do we need phylogenetic taxonomy? Zool. Scripta, 1996, 25, 183-185.

[31] Lee, M.S.Y. The phylogenetic approach to biological taxonomy: practical aspects. Zool. Scripta, 1996, 25, 187-190.

[32] Kron, K.A. Exploring alternative systems of classification. Aliso, 1997, 15, 105-112.

[33] Sundberg, P.; Pleijel, F. Phylogenetic classification and the definition of taxon names. Zool. Scripta, 1994, 23, 19-25.

[34] Benton, M.J. Stems, nodes, crown clades, and rank-free lists: is Linnaeus dead? Biol. Rev. Camb. Philos. Soc., 2000, 75, 633-648.

[35] Stamos, D.N. Pre-DarwiniaN taxonomy and essentialism - A reply to Mary Winsor. Biol. Philos., 2005, 20, 79-96.

[36] Whewell, W. The philosophy of the inductive sciences, Johnson Reprint Corporation: New York, 1967.

[37] Mishler, B.D.; Brandon, R.N. Individuality, pluralism, and the phylogenetic species concept. Biol. Philos., 1987, 2, 397-414.

[38] De Queiroz, K.; Donoghue, M.J. Phylogenetic systematics and the species problem. Cladistics, 1988, 4, 317-338.

[39] Ridley, M. The cladistic solution to the species problem. Biol. Philos., 1989, 4, 1-16.

[40] Hull, D.L. The effect of essentialism on taxonomy - two thousand years of stasis. Br. J. Philos. Sci., 1965, 15, 314-326.

[41] Sneath, P.H.A. Some aspects of Adansonian classification and of the taxonomic theory of correlated features. Ann. Microbiol. Enzimol., 1958, 8, 261-268.

[42] Sokal, R.R.; Sneath, P.H.A. Principles of numerical taxonomy, W. H. Freeman: San Francisco, 1963.

[43] Winsor, M.P. Setting up milestones: Sneath on Adanson and Mayr on Darwin. In Milestones in systematics; Williams, D.M.; Forey, P.L., Eds.; CRC Press: Boca Raton, 2004, pp. 1-17.

[44] Vernon, K. A truly taxonomic revolution? Numerical taxonomy 1957-1970. Stud. Hist. Philos. Biol. Biomed. Sci., 2001, 32, 315341.

[45] Mayr, E. Theory of biological classification. Nature, 1968, 22, 545 548.

[46] Müller-Wille, S. Reducing varieties to their species: The Linnaean research program and its significance for modern biology. In Carl Linnaeus and enlightened science in Spain; Ruiz, E.N., Corrales, M.P.P., Eds.; Fundacion Bernd Wistedt: Madrid, 1998, pp. 113126.

[47] Vavilov, N.I. The law of homological series in variation. J. Genet., 1922, 12, 47-89.

[48] Sokal, R.R. Typology and empiricism in taxonomy. J. Theor. Biol., 1962, 3, 230-267.

[49] Vasilyeva, L.N. Systematics in mycology. Bibl. Mycol., 1999, 178, 1-253.

[50] Mayr, E. Principles of systematic zoology, McGraw-Hill: New York, 1969.

[51] Levit, G.S.; Meister, K. The history of essentialism vs. Ernst Mayr's "essentialism story": a case study of German idealistic morphology. Theor. Biosci., 2006, 124, 281-307.

[52] Hammen, L. Type-concept, higher classification and evolution. Acta Biotheor., 1981, 30, 3-48.

[53] Hagemann, W. Morphology and phylogeny - homology and homophyly. In Abstracts of the XVI International Botanical Congress: 17 August 1999; St. Louis, 1999; p. 22.

[54] Mueller, B.; Engard, C.J. Goethe's botanical writings. University of Hawaii Press, Honolulu, 1952.

[55] Hammen, L. A structuralist approach in the study of evolution and classification. Zool. Mededel., 1985, 59, 391-409.

[56] Hammen, L. Structuralism in evolutionary biology and systematics. Riv. Biol/Biol. Forum, 1987, 80, 216-220, 377-408. 
[57] Resnik, D. The rebirth of rational morphology: process structuralism's philosophy of biology. Acta Biotheor., 1994, 42, 1-14.

[58] Ho, M.W.; Saunders, P.T. Rational taxonomy and the natural system with particular reference to segmentation. Acta Biotheor., 1993, 41, 289-304.

[59] Ghiselin, M.T. A radical solution to the species problem. Syst. Zool., 1974, 23, 536-554.
[60] Ghiselin, M.T. Species concepts, individuality, and objectivity. Biol. Philos., 1987, 2, 127-143.

[61] Hull, D.L. Are species really individuals? Syst. Zool., 1976, 25, 174-191.

[62] Hull, D.L. A matter of individuality. Philos. Sci., 1978, 45, 335360.

(C) Vasilyeva and Stephenson; Licensee Bentham Open.

This is an open access article licensed under the terms of the Creative Commons Attribution Non-Commercial License (http://creativecommons.org/licenses/by-nc/3.0/) which permits unrestricted, non-commercial use, distribution and reproduction in any medium, provided the work is properly cited. 